\title{
ANÁLISE JURÍDICO FUNDIÁRIA EM CIDADES DA MESORREGIÃO POTIGUAR: APONTAMENTOS DE INSTRUMENTOS LEGAIS PARA A PROMOÇÃO DA REGULARIZAÇÃO FUNDIÁRIA DE INTERESSE SOCIAL
}

Land Legal Analysis in Cities of Mesoregion Potiguar : Notes From Legal Instruments For The Promotion Of Regularization of social interest.

\section{Carla Caroline Alves Carvalho ${ }^{1}$ e Almir Mariano Sousa Junior ${ }^{2}$ Daniela de Freitas Lima $^{3}$ Manoel Mariano Neto da Silva ${ }^{4}$}

\begin{abstract}
${ }^{1}$ Graduanda em Ciência e Tecnologia, Universidade Federal Rural do Semi-Árido, Pau dos Ferros, RN, Brasil ${ }^{2}$ Doutorando, Departamento de Ciência e Tecnologia, Universidade Federal Rural do Semi-Árido, Pau dos Ferros, RN, Brasil

${ }^{3}$ Graduanda em Ciência e Tecnologia, Universidade Federal Rural do Semi-Árido, Pau dos Ferros, RN, Brasil ${ }^{4}$ Graduando em Ciência e Tecnologia, Universidade Federal Rural do Semi-Árido, Pau dos Ferros, RN, Brasil
\end{abstract}

\section{Resumo}

Considerando o predominante quadro de informalidade urbana no Brasil é importante notar que esse fato está associado com a ocupação da população em situação de vulnerabilidade socioecômica. A moradia regular é um direito social que integra outros direitos constitucionais como o trabalho, lazer, educação e saúde. Nessa perspectiva, é a partir da implantação da regulariza ção fundiária de interesse social que surge a oportunidade de mudar a história, dado que ao morar regularmente é possível fazer parte efetivamente da cidade. Portanto, estudar a área a ser regularizada observando todos os seus aspectos é imprescindível para a determinação de um instrumento que melhor se adeque a cada realidade e assim reduzir custos, tempo e ganhar qualidade no serviço prestado. Diante disso, essa pesquisa tem como objetivo realizar uma análise jurídico fundiária de municípios da mesorregião potiguar, Estado do Rio Grande do Norte e a partir de então apontar os instrumentos legais a serem utilizados na regularização Fundiária de Interesse Social. Para efetivação dessa pesquisa adota-se quanto ao método de abordagem um estudo qualitativo e quantitativo, quanto ao objetivo um estudo de caso e por fim, quanto aos procedimentos adotados na coleta de dados trata-se de uma pesquisa documental e de campo.

Palavras-chave: Regularização Fundiária de Intesse Social. Análise Jurídico Fundiária. Instrumentos legais. Mesorregião Potiguar.

Abstract

Considering the predominant urban informal framework in Brazil is important to note that this fact is associated with the occupation of the population socioecômica vulnerable. Regular housing is a social right that integrates other constitutional rights such as work, leisure, education and health. In this perspective, it is from the implementation of regularization of social interest that comes the opportunity to change history, because to live regularly can actually be part of the city. Therefore, studying the area to be regularized observing all its aspects is essential to the determination of an instrument best suited to each situation and thus reduce costs, time and gain quality in the service provided. Thus, this research aims to carry out a legal analysis of land municipalities of Natal meso, State of Rio Grande do Norte and from then point out the legal instruments to be used in Land regularization of social interest. For realization of this research is adopted as the method of approach a qualitative and quantitative study on the goal a case study and finally, as the procedures used in the data collection it is a documentary research and field. 


\section{Introdução}

O intenso processo de urbanização brasileira, que aconteceu em pouco mais de 50 anos na segunda metade do século XX, chegou a 2010 com mais de $84 \%$ da sua população vivendo em áreas consideradas urbanas (IBGE, 2012). Associado a isso surgem as diferentes problemáticas neste meio, das quais pode-se destacar a irregularidade fundiária urbana, a qual chega a ser considerada como fator estrutural das cidades brasileiras em virtude de que dentre os 56,7 milhões de domicílios urbanos, isto é, 31,8\% são irregulares (IBGE 2012).

Diante disso, o nordeste concentra a maior quantidade de irregularidade fundiária em domicílios urbanos, com uma porcentagem de 33\%. Destes, o Rio Grande do Norte, por sua vez, possui entre 200 mil e 500 mil. Segundo Fernandes (2011), a informalidade é gerada em virtude de diferentes causas, entre elas estão: baixos níveis de renda, planejamento urbano impraticável, falta de terrenos com fornecimento de serviços de rede pública e habitações de cunho sociais, e um sistema jurídico deficiente. $\mathrm{O}$ autor alerta ainda sobre as sérias consequências que tal situação infere sobre os residentes que vão desde a insegurança da posse, a falta de serviços públicos, a discriminação, prejuízos ambientais, perigos à saúde, desigualdade aos direitos civis.

A urbanização dos assentamentos ilegais constitui uma importante alternativa, para levar melhores condições de vida a uma expressiva parcela da população brasileira a partir da atenuação das desigualdades sociais existentes no país. A regularização fundiária, por sua vez, representa um complemento natural da urbanização, tendo em vista que somente regulamentando juridicamente é possível reconhecer os moradores dessas áreas como cidadãos.

Segundo o Artigo 6 da Constituição Federal (1988), a moradia regular é um direito social que integra outros direitos constitucionais como o trabalho, lazer, educação e saúde. Nessa perspectiva, é a partir da implantação da regularização fundiária que surge a oportunidade de mudar a história, dado que ao morar regularmente é possível fazer parte efetivamente da cidade, pois assim tem-se acesso aos serviços básicos como água, energia elétrica e saneamento.

Assim, considerando que grande parte dessas áreas é formada por uma população em situação de vulnerabilidade socioeconômica, a regularização fundiária de interesse social surge como oportunidade para o alcance de melhoria na qualidade de vida dessas pessoas em virtude de além de garantir o direito à moradia, também proporciona avanços no tocante aos aspectos jurídicos, sociais, ambientais e urbanísticos no entorno desses domicílios.

No entanto, para que tais benefícios de fato alcancem a população é preciso que todas as etapas de processo de regularização fundiária sejam feitas atendendo aos princípios jurídicos, ambientais, sociais e urbanísticos. Os problemas surgem desde a identificação da área, dado que ao ser definida de maneira incorreta pode-se ter a geração de títulos com área maior ou menor de dominialidade diferente daquela existente in loco, além disso pode-se ter localização incoerente com a realidade o que implica, por exemplo, nas análises socioeconômicas e ambientais do assentamento.

Portanto, analisar bem a área a ser regularizada observando todos os seus aspectos é imprescindível para a determinação de um instrumento que melhor se adeque a cada realidade e assim reduzir custos, tempo e ganhar qualidade no serviço prestado. Além disso, em virtude de ser uma temática recente no país, a pesquisa nessa área tem muito a contribuir para a construção de conhecimento acadêmico e que por consequência, afetam a comunidade ao passo que políticas públicas continuem sendo tomadas no intuito de permitir a população o acesso a tal direito, melhorando portanto sua qualidade de vida no que diz respeito as condições sociais, ambientais, econômicas e jurídicas.

Sendo assim, essa pesquisa tem como objetivo analisar a situação jurídica fundiária dos municípios de São Miguel e Encanto, da mesorregião potiguar, os quais estão passando pelo processo de regularização fundiária urbana de interesse social por meio do Programa Acesso à Terra Urbanizada, 
que é um projeto de extensão e de pesquisa financiado pelo Ministério da Educação e Ministério das Cidades e institucionalizado pela Universidade Federal Rural do Semi-Árido (UFERSA), Campus Pau dos Ferros

\section{Entendendo a Regularização Fundiária Urbana de Interesse Social}

As primeiras décadas do século XX protagonizaram a consolidação de um intenso processo de urbanização que permeou não somente o território brasileiro como também o da América Latina. Nessas circunstâncias, vale ressaltar que, em solo brasileiro, a emergência do trabalhador livre, a proclamação da República e o tímido crescimento da indústria, ainda associada as necessidades básicas do mercado interno, foram fatores que impulsionaram essa urbanização. Paralelo a isso, aconteceram as constantes reformas urbanas, final do século XIX e início do século XX, que tinham o objetivo de eliminar epidemias por meio de obras de saneamento básico e o embelezamento paisagístico e para tanto, expulsaram a população, em situação de vulnerabilidade socioeconômica, para as periferias das cidades.

O fortalecimento do mercado interno, trazido pela industrialização em 1930, modernizou as forças produtivas e levou a profundas mudanças no estilo de vida da população, massificando assim o consumos de bens, aos quais em tempos anteriores apenas aqueles com renda alta tinham acesso. Isso, porém, não foi suficiente para promover a abertura dos mercados à maioria da população que desejava ter acesso a moradia, em virtude da riqueza se manter concentrada. Além disso, entre as décadas de 1980 de 1990 houve a desaceleração do crescimento econômico que intensificou a desigualdade social e concentrou a pobreza nas áreas urbanas.

As intensas migrações internas no país aconteceram no sentido campo cidade e principalmente para os centros metropolitanos do país, principalmente os da região sudeste. Na segunda metade do século XX, as cidades brasileiras, principalmente as metrópoles, receberam 120 milhões de novos habitantes. No entanto, elas não estavam preparadas para receber essa alta quantidade de pessoas, dado que não tinham como oferecer recursos, infraestrutura e serviços suficientes. A população ao chegar na cidade se depara com baixas ou nenhuma renda, mercado imobiliário elitista, uma legislação que contribui para a reprodução desse mercado, entre outros fatores que impossibilitaram o acesso destas pessoas a uma moradia devidamente enquadrada na lei.

Dentro do processo de crescimento urbano surgem a cidade legal e a cidade ilegal. A cidade legal é compreendida pela parte da cidade que tem acesso as ações do poder público, no que se refere a assessoria nas necessidades de infraestrutura, além disso, é também valorizada pelo mercado imobiliário. Enquanto isso, a cidade ilegal vem para mostrar a irregularidade do ambiente urbano, para Maricato (2003) na ilegalidade urbanística a exclusão da população é um todo: social, econômica, ambiental, jurídica e cultural. Isso dificulta a resolução de conflitos, dado que não há lei, julgamentos formais ou Estado, de forma que dificulta o acesso a infraestrutura urbana, justiça oficial, lazer, educação, entre outros benefícios.

Portanto, as contradições presentes na cidade ilegal enfatizam os processos de segregação socioespacial e fragmentação sofridos ao longo de todo o percurso histórico de formação das cidades. As territorialidades construídas pela relação entre os diferentes agentes sociais fragmentam o espaço habitado que, por consequência gera a segregação sociosespacial e exclui grande parte da população aos serviços de infraestrutura urbana, justiça social, educação, economia, cultura e lazer, ou seja, segrega os indivíduos em um contexto como o todo.

A ilegalidade urbanística provoca a segregação territorial que exclui os moradores dos assentamentos precários em um completo contexto, isto é, nos âmbitos social, econômico, ambiental, jurídico e cultural. Desse modo, a informalidade urbana fere os direitos sociais previstos no artigo 6 da Constituição Federal de 1988. É declarado como direito social a educação, a saúde, a alimentação, o trabalho, a moradia, o lazer, a segurança, a previdência social, a proteção à maternidade e à infância e a assistência aos desamparados. Nota-se, portanto, que a preservação dos direitos sociais implica em uma profunda mudança na realidade. Segundo Maior (2013, p.152) 
A função do direito social é distribuir a riqueza, para fins não apenas de eliminar, por benevolência, a pobreza, mas para compor o projeto de uma sociedade na qual todos possam, efetivamente, adquirir, em sua significação máxima, o sentido da cidadania, experimentando a beleza da condição humana, sendo certo que um dos maiores problemas que agridem a humanidade é a injustiça.

Logo, a promoção de políticas públicas voltadas para a urbanização das cidades, implicam na atenuação das desigualdades sociais na finalidade de construir cidades nas quais seus habitantes tenham a possibilidade de exercer sua cidadania. De acordo com Seabrook (1996 apud Harvey, 2013) a cidade sempre representou o lugar do encontro das diferenças e da interação criativa, nas quais diversas culturas e desejos individuais se chocam de modo que os usos e visões constituem a desordem. Sendo assim, abrir as portas da cidade para grande parte da sua população que encontra-se a margem social e espacialmente deste lugar. É nesse sentido que se constrói a discussão sobre o direito a cidade, sobre isso Harvey (2013) discute que:

O direito à cidade, como comecei a dizer, não é apenas um direito condicional de acesso àquilo que já existe, mas sim um direito ativo de fazer a cidade diferente, de formá-la mais de acordo com nossas necessidades coletivas (por assim dizer), definir uma maneira alternativa de simplesmente ser humano. Se nosso mundo urbano foi imaginado e feito, então ele poder ser reimaginado e refeito. (HARVEY, 2013, p. 58)

Neste sentido reorganizar a cidade a partir de um efetivo processo de urbanização é garantir a preservação dos direitos socais e possibilitar a participação efetiva da população em sua construção. Dentre práticas reformadoras estão as políticas públicas urbanas e de habitação, são elas que permitem o alcance do direito à moradia. Este, enquanto direito social, é definido pelo Comitê dos Direitos Econômicos, Sociais e Culturais da ONU através do Comentário Geral oo 4 mostrando que são necessários sete componentes para garantir com eficácia o direito à moradia. Estes, por sua vez, são: segurança jurídica da posse, habitabilidade, disponibilidade de serviços e infraestrutura, custo acessível da moradia, acessibilidade, localização e adequação cultural.

Mediante a tal definição é possível perceber a relação com a questão da estabilidade da posse que por sua vez é intrínseca ao processo de regularização fundiária. Em termos gerais, a regularização fundiária é um conjunto de medidas jurídicas, urbanísticas, ambientais e sociais que tem como principal objetivo tornar legal os assentamentos irregulares.

No geral acontecem duas situações na irregularidade fundiária que são: a irregularidade dominial e, urbanística e ambiental. Na primeira o possuidor ocupa um terra (pública ou privada) sem possuir nenhum tipo de título que lhe possibilite uma garantia jurídica sobre essa posse. Enquanto isso, a segunda se dá quando o parcelamento não está conforme a legislação urbanística e ambiental e, por consequência, não foi licenciado. Deste modo, para integrar totalmente esses assentamentos à cidade é preciso vencer todas essas questões. Para tanto, a Lei Federal no 11.977/2009 declara:

Art. 46. A regularização fundiária consiste no conjunto de medidas jurídicas, urbanísticas, ambientais e sociais que visam à regularização de assentamentos irregulares e à titulação de seus ocupantes, de modo a garantir o direito social à moradia, o pleno desenvolvimento das funções sociais da propriedade urbana e o direito ao meio ambiente ecologicamente equilibrado.

Considerando ainda que a regularização fundiária é um instrumento que garante a cidadania, se torna evidente a necessidade de estar interligada a outras políticas públicas. No tocante a isso a Lei no 11.977/2009 determina ainda os seguintes princípios:

I - ampliação do acesso à terra urbanizada pela população de baixa renda, com prioridade para sua permanência na área ocupada, assegurados o nível adequado de habitabilidade e a melhoria das condições de sustentabilidade urbanística, social e ambiental;

II - articulação com as políticas setoriais de habitação, de meio ambiente, de saneamento básico e de mobilidade urbana, nos diferentes níveis de governo e com as iniciativas públicas e privadas, voltadas à integração social e à geração de emprego e renda;

III - participação dos interessados em todas as etapas do processo de regularização;

IV - estímulo à resolução extrajudicial de conflitos; e

$\mathrm{V}$ - concessão do título preferencialmente para a mulher. 
Vale ressaltar ainda que a irregularidade, apesar de estar comumente ligada a população de menor poder aquisitivo, notadamente caracterizada no perfil dos assentamentos populares, também acontece em loteamentos ocupados por famílias de média e alta renda que não estão de acordo com a lei. É por falta de alternativa que os moradores dos assentamentos precários se veem obrigados a ocupar esses espaços, enquanto que nos demais casos, existe a oportunidade de habitar condomínios e loteamentos regulares, dado que possuem condições financeiras para isso. É necessário portanto, para o alcance de um ordenamento legal que compreenda toda a cidade, regularizar esses dois casos de ocupação ilegal.

No tocante a tal problemática, a Lei n⿳o 11.977/2009 define dois tipos de regularização fundiária, que são a de interesse social e a de interesse específico. A regularização fundiária de interesse social: utilizada em assentamentos irregulares ocupados pela população com baixo poder aquisitivo, no qual a preservação do direito constitucional à moradia justifica a aplicação de instrumentos, procedimentos e requisitos técnicos especiais. Enquanto isso, a regularização fundiária de interesse específico se aplica a assentamentos diferentes daqueles descritos como de interesse social. Logo, nestes assentamentos, não são utilizados procedimentos especiais como acontece na regularização fundiária de interesse social.

Na regularização fundiária de interesse social, os assentamentos precisam estar declarados como áreas de interesse para a implantação de projetos desse tipo de regularização, como é o caso de áreas da União, dos estados, do Distrito Federal ou dos municípios. Podem ainda estar localizados em Zonas Especiais de Interesse Social - ZEIS. Além disso, deve atender aos requisitos para usucapião ou concessão de uso especial para fins de moradia.

Os instrumentos e mecanismos específicos para a regularização fundiária de interesse social são definidos pela Lei $\mathrm{n}^{\mathrm{o}}$ 11.977/2009 no intuito de tornar mais eficiente a concretização do direito à moradia, que são: a demarcação urbanística, a legitimação de posse e a regularização fundiária de Áreas de Preservação Permanente - APP's.

A demarcação urbanística constitui-se como a delimitação de uma área ocupada com a finalidade habitacional, podendo ser de dominialidade pública ou privada, de maneira que a partir do reconhecimento de seus limites, confrontantes, área de superfície bem como a sua localização é possível proceder com os processos de regularização fundiária de interesse social (Ministério das Cidades, 2010). Esse instrumento pode ser empregado pelo poder público, sendo este representado nas esferas de munícipios, estados, Distrito Federal e a União. Porém, dentro dessas representações existem limites onde cada um pode ou não atuar, como mostra a tabela 1:

Tabela 1 - Áreas onde cada esfera do poder público pode demarcar

\begin{tabular}{cccc}
\hline & $\begin{array}{c}\text { Município pode } \\
\text { Demarcar }\end{array}$ & $\begin{array}{c}\text { Estado pode } \\
\text { demarcar }\end{array}$ & $\begin{array}{c}\text { União pode } \\
\text { demarcar }\end{array}$ \\
\hline Áreas Particulares & Sim & Sim & sim \\
\hline $\begin{array}{c}\text { Áreas Públicas } \\
\text { Municipais }\end{array}$ & Sim & $\begin{array}{c}\text { Sim } \\
\text { (com a concordância } \\
\text { do ente municipal) }\end{array}$ & $\begin{array}{c}\text { (com a concordância } \\
\text { do ente municipal) }\end{array}$ \\
\hline $\begin{array}{c}\text { Áreas Públicas } \\
\text { Estaduais }\end{array}$ & $\begin{array}{c}\text { (com a concordância } \\
\text { do ente estadual) }\end{array}$ & Sim & $\begin{array}{c}\text { Sim } \\
\text { (com a concordância } \\
\text { do ente estadual) }\end{array}$ \\
\hline $\begin{array}{c}\text { Áreas Públicas } \\
\text { Federais }\end{array}$ & Não & Não & Sim \\
\hline
\end{tabular}

Fonte: adaptado de Ministério das Cidades (2010)

A legitimação de posse, por sua vez, é utilizada no intuito de reconhecer a posse dos moradores residentes em áreas que passaram por demarcação urbanística (LEI 11.977, 2009). O título gerado por esse instrumento não reconhece um direito real, dessa forma, a sua aplicação em áreas públicas é interessante somente quando o ente promotor da ação não é o proprietário do imóvel. Sendo assim, 
quando a ação é realizada pelo próprio detentor do domínio, por exemplo, o município que está atuando em áreas de dominialidade municipal, a legitimação de posse não se faz necessária dado que é possível realizar a transferência do direito real a partir de instrumentos como a CUEM (Concessão de Uso Especial para Fins de Moradia), a CDRU (Concessão do Direito Real de Uso), doação, entre outros.

Em muitos casos a ocupação se deu em uma área caracterizada como área de preservação permanente (APP'S), definidas de acordo com a Lei Federal no 4.771/65 - Código Florestal. A Lei Federal no 11.977/2009, por sua vez, abre a possibilidade para a regularização dessas áreas, sob algumas condições: a ocupação da APP deve ser anterior a 31 de dezembro de 2007, o assentamento precisa estar inserido em uma área urbana consolidada bem como, deve ser feito um estudo técnico que comprove a melhoria das condições ambientais em condição a situação de ocupação anterior a partir da intervenção do programa.

\section{Resultados e Discussões}

Dentre as $10(\mathrm{dez})$ cidades trabalhadas pelo Programa Acesso à Terra Urbanizada, estão os municípios de São Miguel e Encanto, todas localizadas na mesorregião do oeste potiguar. Para dar início ao processo de regularização o programa realizou um diagnóstico, juntamente com o poder público municipal, das possíveis áreas a sofrerem intervenção em cada município. Na cidade de São Miguel foram selecionadas duas áreas de domínio municipal: Vila Tôta Barbosa e Vila Nossa Senhora de Guadalupe, os quais seguem, respectivamente a suas plantas de situação:

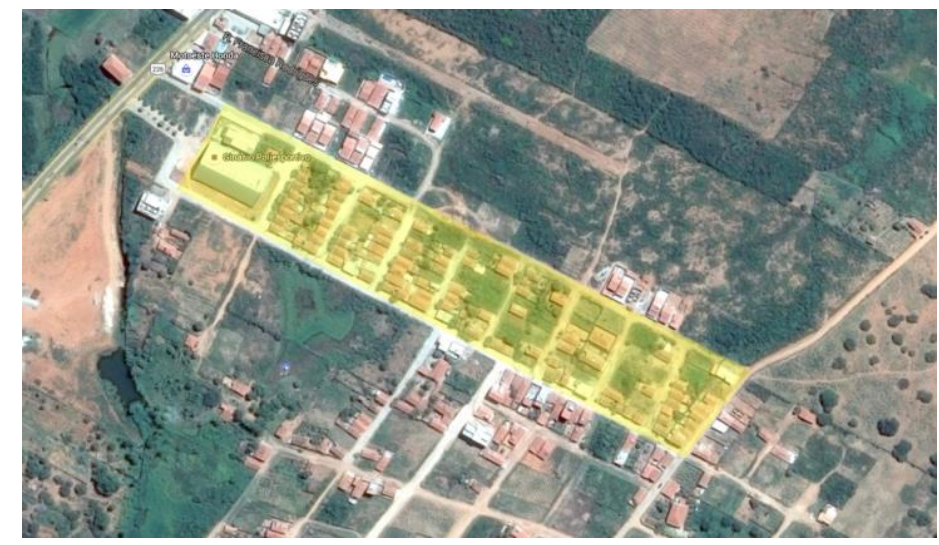

Figura 1 - Planta de Situação da Vila Tôta Barbosa, São Miguel/RN Fonte: Programa Acesso à Terra Urbanizada, 2015.

O assentamento mostrado na figura 1, foi ocupado entre 1992 e 1996, período no qual se deu a construção de residências e concedido o direito de urso por meio de carta de aforamento por um período de 20 anos a partir de 1996. 


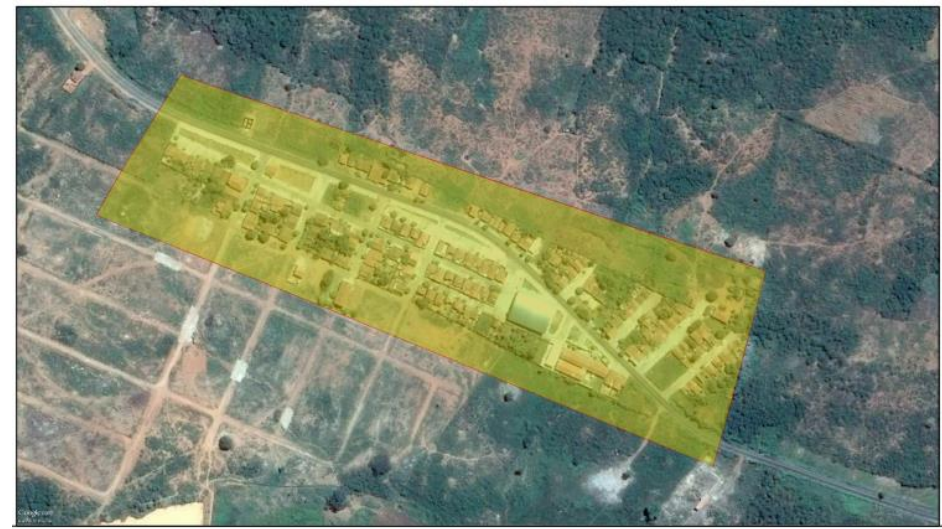

Figura 2 - Planta de Situação da Vila Nossa Senhora de Guadalupe, São Miguel/RN

Fonte: Programa Acesso à Terra Urbanizada, 2015.

O assentamento da Vila Nossa Senhora de Guadalupe foi adquirido pelo município no ano de 1985. Sete anos mais tarde foi concedido o direito de uso por meio de carta de aforamento por um período de 20 anos a partir de 1992. Vale ressaltar que com o passar do tempo muitos moradores se instalaram em outros bairros e passaram o direito de uso para outras pessoas, por meio do termo de aquiescência. Algumas residências foram construídas e doadas pelo municípios e outras pelos próprios moradores.

Na cidade de Encanto, foram selecionadas os assentamentos Antônio Cajazeiras e o São Luiz. O Antônio Cajazeiras foi adquirido pelo município em 2010 de forma que as suas residências foram construídas por meio dos programas habitacionais Minha Casa Minha Vida I e Minha Casa Minha II, a figura 3 mostra a planta de situação do bairro:

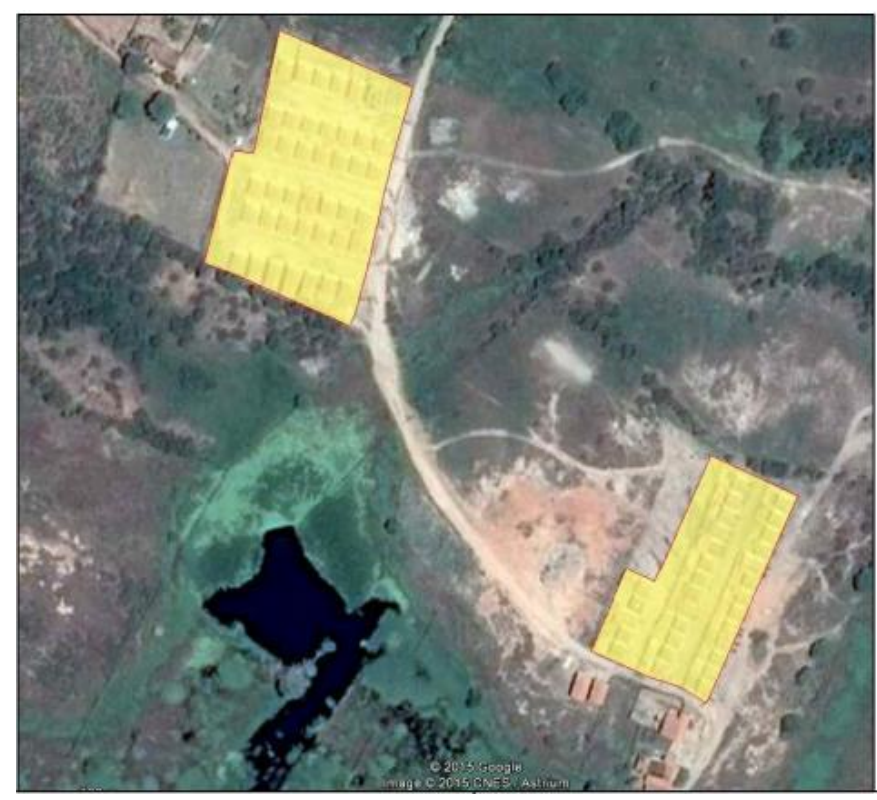

Figura 3 - Planta de Situação do Antônio Cajazeiras, Encanto/RN Fonte: Programa Acesso à Terra Urbanizada, 2015.

O assentamento São Luiz, por sua vez, constitui-se como um dos bairros mais antigos da cidade e foi ocupado sem a presença de programas habitacionais, apenas por meio da doação ou 
autorização da prefeitura para uso com fins de moradia. A planta de situação desse assentamento está representada na figura 4:

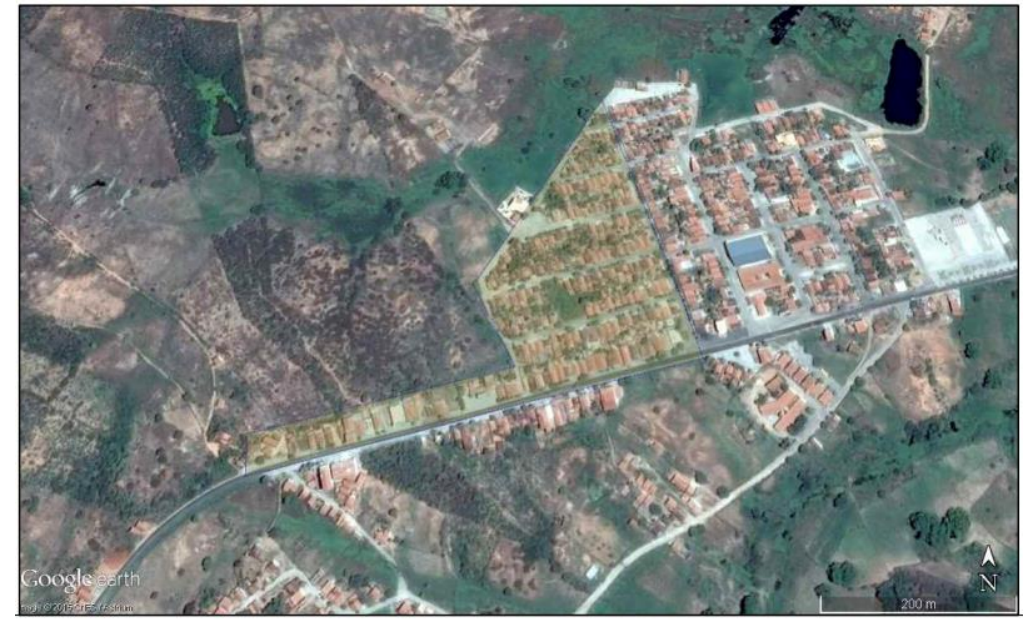

Figura 4 - Planta de Situação do São Luiz, Encanto/RN Fonte: Programa Acesso à Terra Urbanizada, 2015.

Definidos os assentamentos, deu-se início ao trabalho social para comunicar as lideranças comunitárias e a comunidades como um todo do que iria acontecer em seus respectivos bairros, benefícios, requisitos necessários para participar, entre outras informações. Em seguida, foi realizada a cartografia básica de cada assentamento urbano a ser trabalhado. Essa etapa consiste na elaboração de levantamento planimétrico/planialtimétrico cadastral georrefenciado, a partir de topografia, em escala apropriada.

Em seguida, se deu a etapa de regularização da base imobiliária, a qual é definida, de acordo com o Programa Acesso à Terra Urbanizada (2015), como a elaboração de documentos técnicos, administrativos e jurídicos para a regularização da base imobiliária do assentamento irregular. Assim, é feita a sobreposição da situação de fato com a situação de registro, da situação atual com a situação pretendida, bem como a fundamentação técnica e jurídica para a regularização fundiária, entre outros.

Em São Miguel, o assentamento Nossa Senhora de Guadalupe, contém 164 lotes e está registrado no Primeiro Cartório de Ofício de Notas de São Miguel/RN com matrícula sob no 196, livro 2-b, fls 15, a planta cartográfica dessa área está representada na figura 5: 


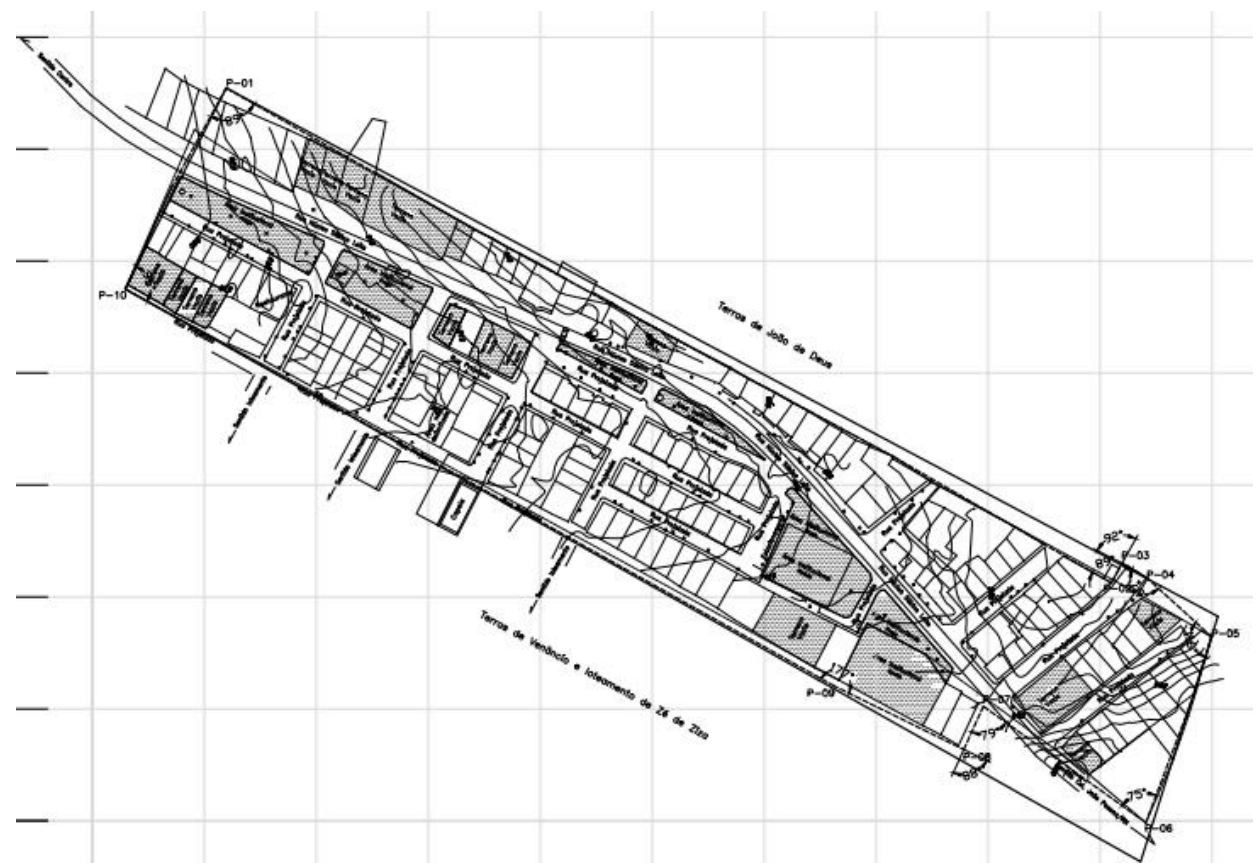

Figura 5 - Planta Cartográfica Nossa Senhora de Guadalupe, São Miguel/RN Fonte: Programa Acesso à Terra Urbanizada, 2015.

Para melhor comprender a delimitação dessa área, é importante observar a figura 6 e a tabela 2 que trazem, respectivamente, a as poligonais de interesses e suas dimensões:

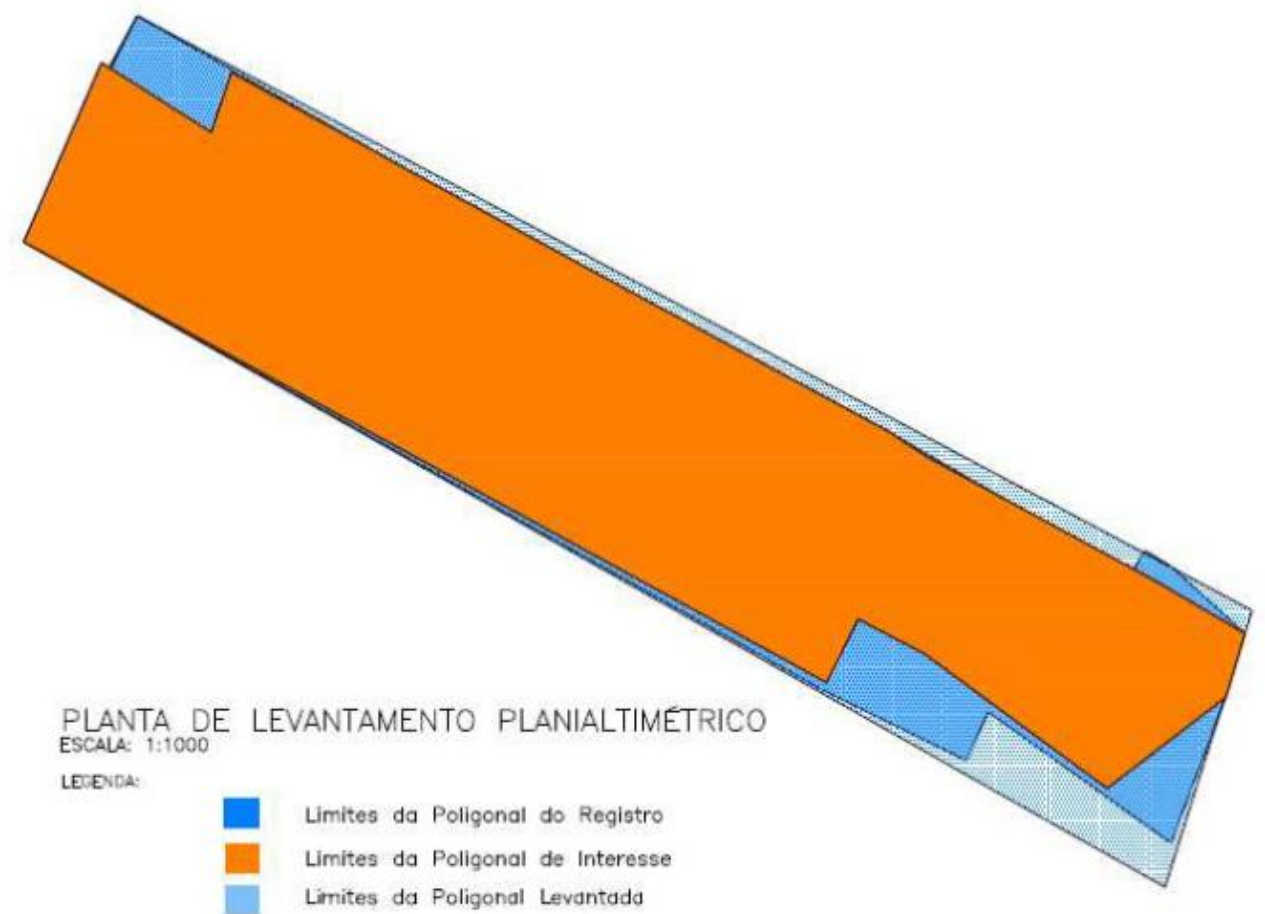

Figura 6 -Poligonais registradas, levantadas e de interesse do Nossa Senhora de Guadalupe, São Miguel/RN Fonte: Programa Acesso à Terra Urbanizada, 2015. 
Tabela 2 - Áreas e Perímetros Nossa Senhora de Guadalupe

\begin{tabular}{ccc}
\hline & Áreas da Poligonal Levantada & \\
\hline ÁREA $\left(\mathrm{m}^{2}\right): 56.996,48$ & ÁREA (ha): 5,7 & Perímetro $(\mathrm{m}): 1287,94$ \\
\hline & Áreas da Poligonal Registrada & \\
\hline ÁREA $\left(\mathrm{m}^{2}\right): 54.450,00$ & ÁREA (ha): 5,4 & Perímetro $(\mathrm{m}): 933,38$ \\
\hline & Área da Poligonal de Interesse & \\
\hline ÁREA $\left(\mathrm{m}^{2}\right): 51.525,71$ & ÁREA (ha): 5,15 & Perímetro (m): 1165,16 \\
\hline
\end{tabular}

Diante disso, pode-se notar que as áreas registrada e de interesse evidenciadas na figura 7 possuem dimensões aproximadamente iguais, sendo que a registrada possui uma área de $54.450,00 \mathrm{~m}^{2}$ e a de interesse com 51.525,71 $\mathrm{m}^{2}$, sendo a primeira maior que a segunda. Logo, se faz necessário destacar a porção a ser regularizada e, consequentemente abrir uma nova matrícula, dado que em virtude da ausência de especificação das dimensões dos lados da proção de terra na matrícula, vito que ela possui o total da área $\left(54.450,00 \mathrm{~m}^{2}\right)$.

A Vila Tôta Barbosa possui registro no Primeiro Cartório de Ofício de Notas do Município de São Miguel/RN no livro 2E, fls 40, com matrícula de número 714. O trabalho de cartografia básica nesse bairro gerou a seguinte planta:

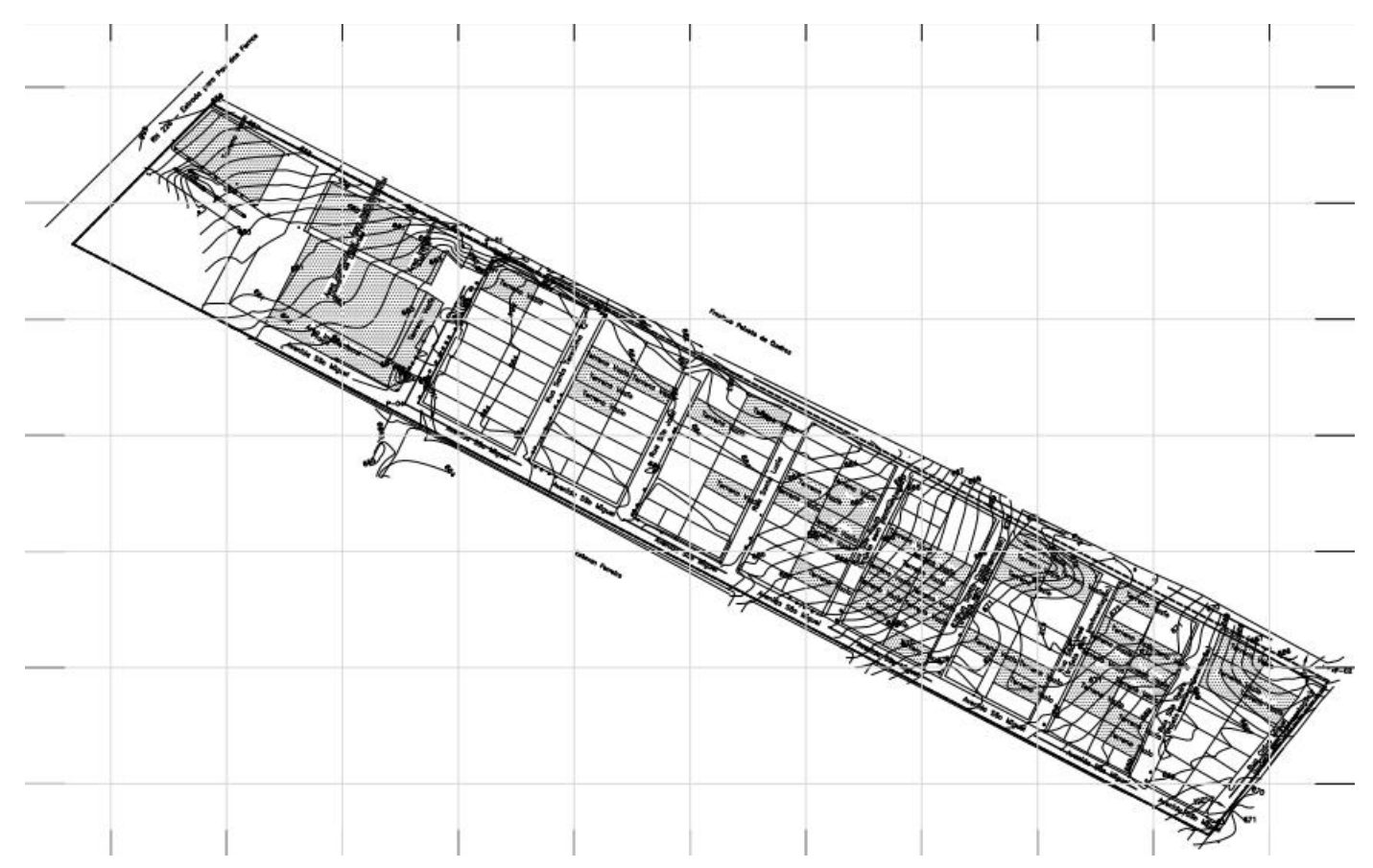

Figura 7 - Planta CartográficaVila Tôta Barbosa, São Miguel/RN Fonte: Programa Acesso à Terra Urbanizada, 2015.

As especificades dessa área são ainda retradas na figura 8 e na tabela 3: 


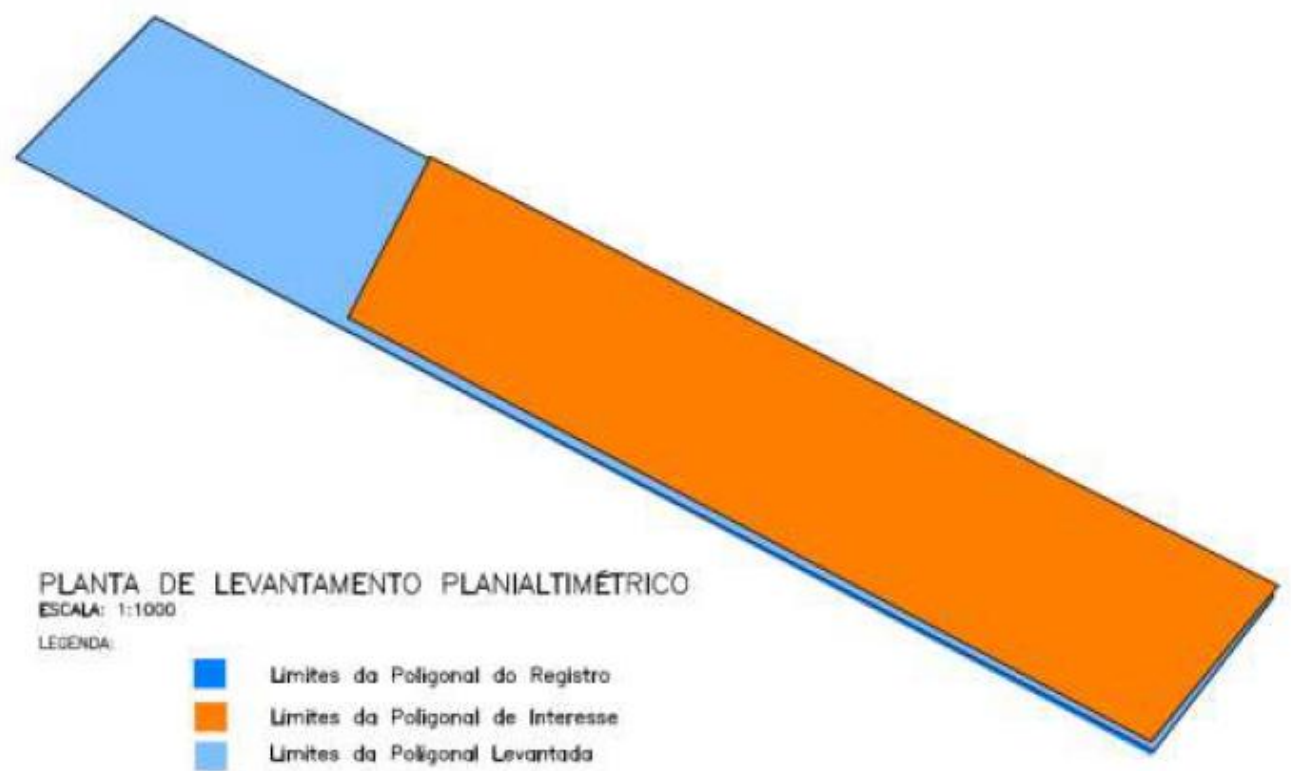

Figura 8 - Poligonais registradas, levantadas e de interesse doTota Barbosa, São Miguel/RN Fonte: Programa Acesso à Terra Urbanizada, 2015.

Tabela 3 - Áreas e Perímetros da Vila Tôta Barbosa

\begin{tabular}{ccc}
\hline & Áreas da Poligonal Levantada & \\
\hline ÁREA $\left(\mathrm{m}^{2}\right): 44.823,80$ & ÁREA (ha): 4,48 & Perímetro $(\mathrm{m}): 1263.53$ \\
\hline & Áreas da Poligonal Registrada & \\
\hline ÁREA $\left(\mathrm{m}^{2}\right): 44.414 .24$ & ÁREA (ha): 4,4 & Perímetro $(\mathrm{m}): 1217,00$ \\
\hline & Área da Poligonal de Interesse & \\
\hline ÁREA $\left(\mathrm{m}^{2}\right): 32.396,02$ & ÁREA (ha): 3,23 & Perímetro (m): 963,60 \\
\hline
\end{tabular}

Nesse caso, ao considerar que a área registrada seja de $44.000 \mathrm{~m}^{2}$ ela será inferior a apontada pelo município, sendo necessário, portanto, a retificação de matrícula. Na figura 9, não é possível distinguir a área registrada e a área levantada porque elas são aproximadamente iguais. É importante observar ainda que na matrícula desse assentamento existe um erro de digitação e uma imprecisão com relação a delimitação dessa área no trecho "mais ou menos $44.00 \mathrm{~m}^{2 \prime \prime}$.

Na cidade de Encanto, por sua vez o assentamento do Antônio Cajazeiras representada na figura 9: 


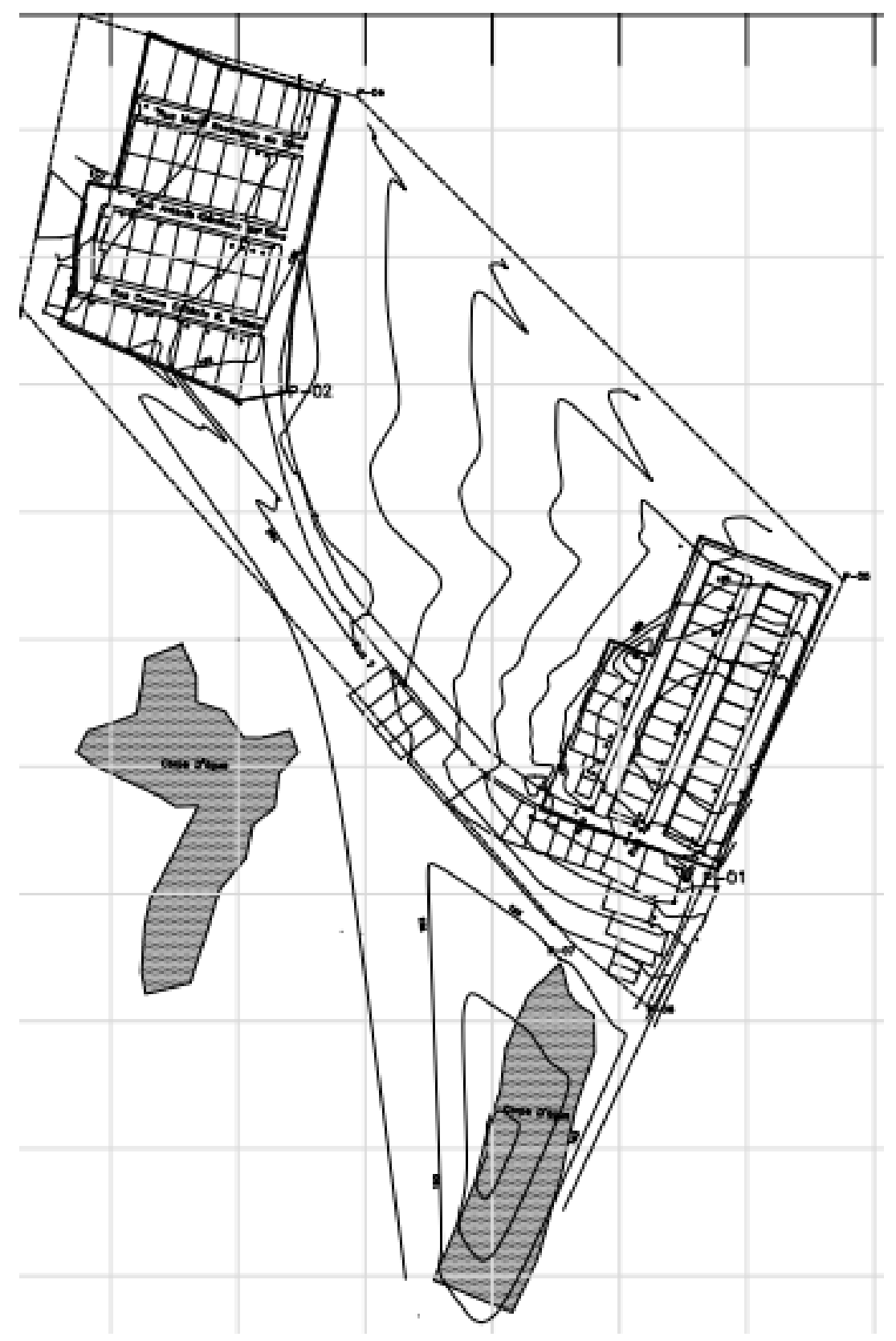

Figura 9 - Planta Cartográfica Antônio Cajazeiras, Encanto/RN Fonte: Programa Acesso à Terra Urbanizada, 2015.

Esse assentamento possui 77 lotes com matrícula registrada no Cartório único de Encanto/RN, documento sob no ${ }^{\circ}$ 210, livro 2-B, fls. 74. Enquanto isso, o São Luiz possui 204 lotes, porém essa área não dispõe de matrícula, ou seja, não está definido em cartório a dominialidade desse assentamento. A falta de registro de glebas em cartório representa uma grande problemática para o processo de regularização fundiária, dado que ao conhecer o domínio de determinadas área, as demais etapas acontecem de maneira mais tranquila. As poligonais e interesse e suas dimensões são mostradas respectivamente na figura 10 e tabela 4. 


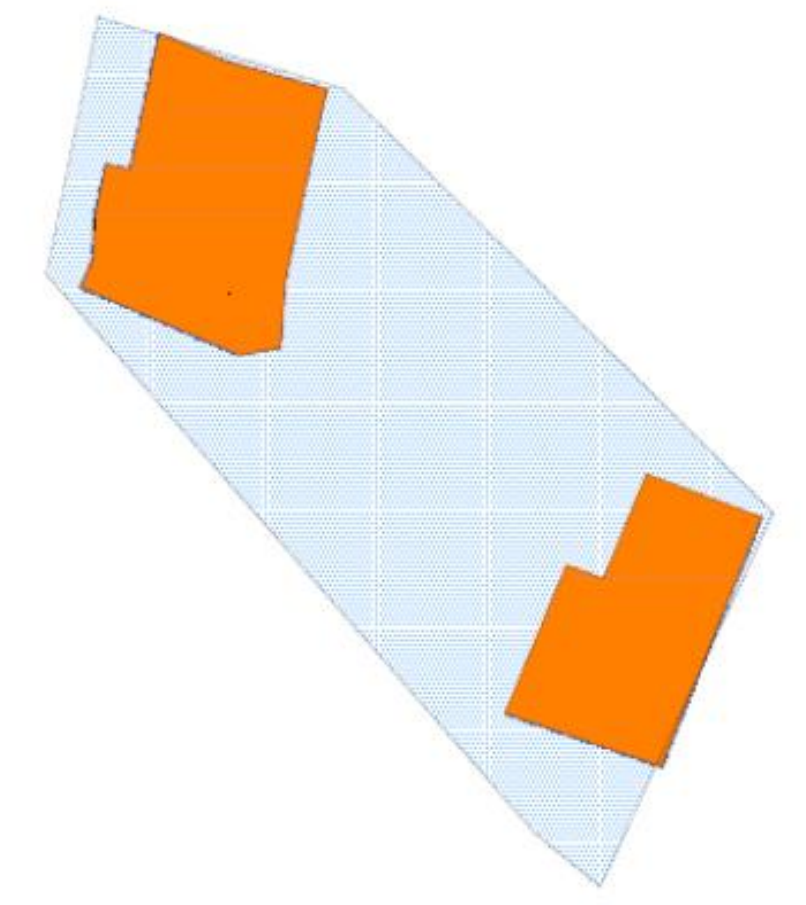

\section{PLANTA DE LEVANTAMENTO PLANIALTIMETRICO Escala: $1: 500$ LECENC:}

\footnotetext{
Limites da Poligonal do Registro

Umites da Poligonal de Interesse

Limites do Poligonal Levantada
}

Figura 10 - Poligonais Levantadas e de Interesse do Antônio Cajazeiras, Encanto/RN Fonte: Programa Acesso à Terra Urbanizada, 2015.

Tabela 4 - Áreas e Perímetros do Antônio Cajazeiras

\begin{tabular}{ccc}
\hline & Áreas da Poligonal Levantada & \\
\hline ÁREA $\left(\mathrm{m}^{2}\right): 59.213,00$ & ÁREA (ha): 5,9 & Perímetro $(\mathrm{m}): 1052,87$ \\
\hline & Áreas da Poligonal Registrada & \\
\hline ÁREA $\left(\mathrm{m}^{2}\right):-$ & ÁREA (ha): - & Perímetro (m): - \\
\hline & Área da Poligonal de Interesse & \\
\hline ÁREA $\left(\mathrm{m}^{2}\right): 18.123,62$ & ÁREA (ha): 1,81 & Perímetro (m): 810,92 \\
\hline
\end{tabular}

A partir da leitura da tabela 4 pode-se notar que a poligonal levantada possui área maior que à de interesse porque na sua composição foram considerados os lotes e uma maior extensão de terra, de forma que se obtém maiores detalhes da área e assim, tem-se melhores análises. Além disso, na linha de poligonal registrada da tabela os valores da área não foram registrados em virtude do fato de que a área de registro fornecida através do documento registrada em cartório não coincide com delimitações reais da porção de terra que abrange todas as residências, o que faz surgir a necessidade de retificação de matrícula.

O assentamento São Luiz - Encanto/RN tem sua planta cartográfica, poligonal de interesse e suas dimensões mostradas na figura 11, figura 12 e tabela 3, respectivamente: 


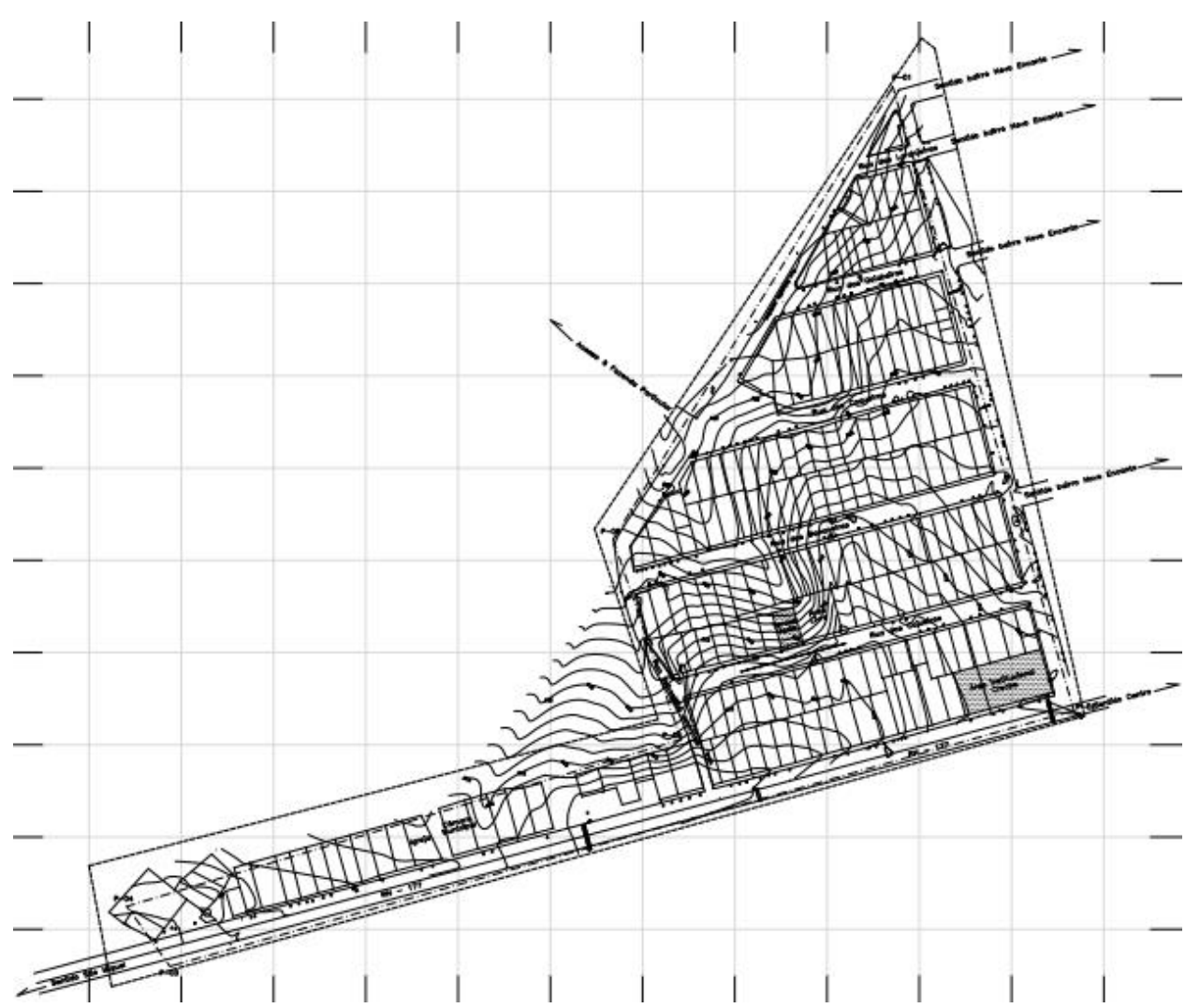

Figura 11 - Planta Cartográfica do São Luiz, Encanto/RN Fonte: Programa Acesso à Terra Urbanizada, 2015.

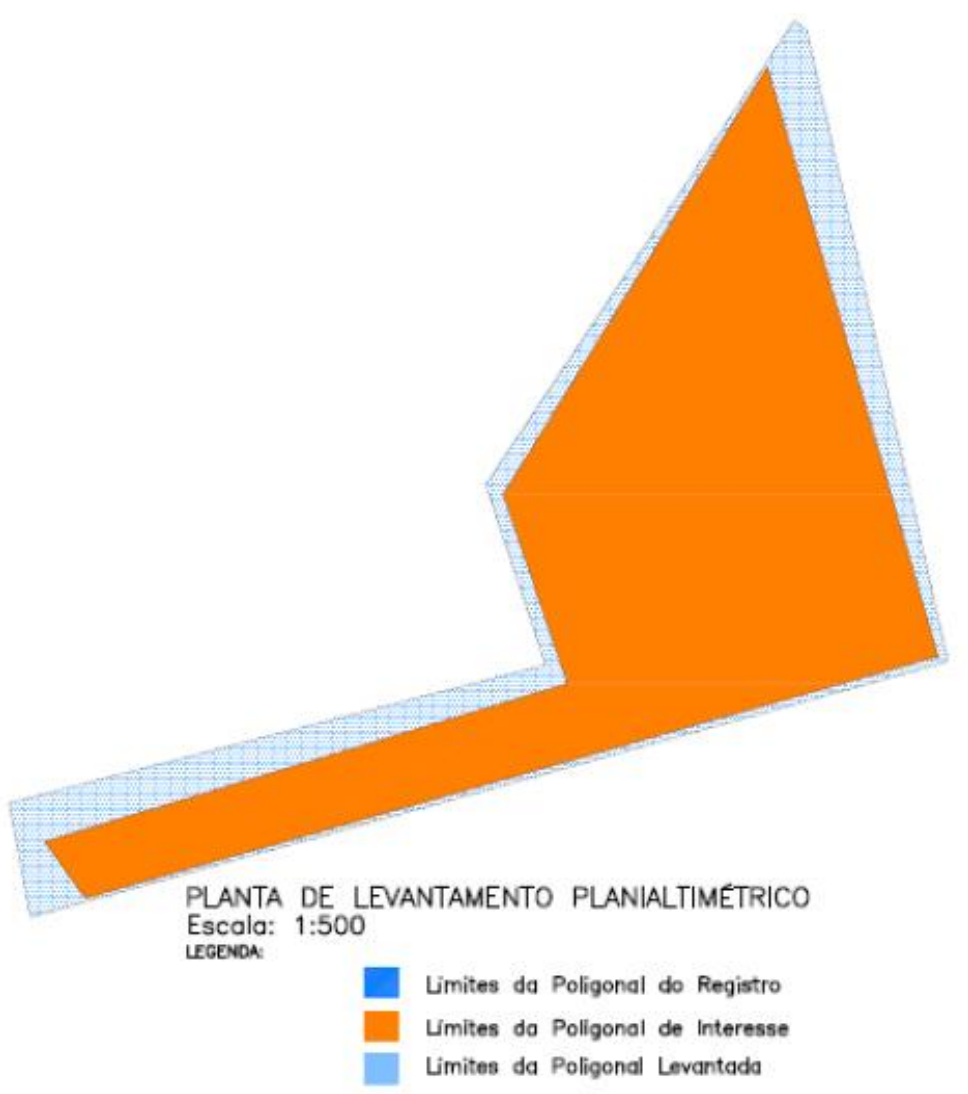

Figura 12 - Poligonais Levantadas e de Interesse do São Luiz, Encanto/RN Fonte: Programa Acesso à Terra Urbanizada, 2015. 
Tabela 5 - Áreas e Perímetros do São Luiz

\begin{tabular}{ccc}
\hline & Áreas da Poligonal Levantada & \\
\hline ÁREA $\left(\mathrm{m}^{2}\right): 66.324,40$ & ÁREA (ha): 6,63 & Perímetro $(\mathrm{m}): 1.617,57$ \\
\hline & Áreas da Poligonal Registrada & \\
\hline ÁREA $\left(\mathrm{m}^{2}\right):-$ & ÁREA (ha): - & Perímetro (m): - \\
\hline & Área da Poligonal de Interesse & \\
\hline ÁREA $\left(\mathrm{m}^{2}\right): 84.387,22$ & ÁREA (ha): 8,43 & Perímetro (m): 1740,74 \\
\hline
\end{tabular}

Considerando que não foi localizado o documento desse assentamento, a delimitação dele se deu por meio de indicação da Prefeitura Municipal de Encanto/RN e da comunidade moradora do bairro. Além disso, foi realizado o detalhamento do entorno o que justifica a diferença entre a área de interesse e a levantada.

Mediante tal caracterização de área pode-se inferir que a cidade de Encanto apresenta um quadro mais complexo que a cidade de São Miguel, dado que um dos assentamentos daquela, o São Luiz, não possui documentação registrada e que por isso precisa passar pelo processo de demarcação urbanística. Enquanto isso, no Antonio Cajazeiras (Encanto-RN) e nos assentamentos de São Miguel, Nossa Senhora de Guadalupe e Tôta Barbosa, será utilizado o instrumento de Concessão do Direito Real de Uso (CDRU), pois a dominialidade é conhecida de modo que é possível fazer a transferência imediata de direito real em nome do possuidor.

A CDRU é definida pelo Decreto de Lei no 271/2009, na qual pode-se compreender que se trata de um contrato no qual se transfere a direito real, o usufruto por prazo certo ou indeterminado, de terreno particular ou público para fins específicos, e nesse caso para o interesse social. Logo, esse instrumento além de reconhecer o direito real de posse ele ainda agiliza o processo de titulação dos moradores.

A demarcação urbanística por sua vez se faz necessária para a regularização do assentamento urbano São Luiz. Segundo Paiva (2012) a demarcação urbanística é o grande instrumento inovador no processo de regularização fundiária de interesse social, pois a partir dele que se tem a possibilidade, conferida ao poder público, de fazer o auto de demarcação urbanística, ou seja, levantamento de situação da área a regularizar e caracterizando a ocupação existente nesse espaço.

Sendo assim, a partir da análise da viabilidade de utilização desse instrumento no assentamento de São Luiz, principalmente no que se refere ao histórico da ocupação bem como a ausência de qualquer oposição a ela. Em seguida elabora-se o auto de demarcação urbanística, representado, em parte, nessa pesquisa pelas plantas de levantamento planialtimétrico e sobreposição desta com os imóveis registrados em cartório. Assim, se faz necessário a elaboração de notificação, pelo Programa Acesso à Terra Urbanizada enquanto promotor da regularização, aos demais entes públicos quando a demarcação alcançar áreas públicas e com ela confrontar (MINISTÉRIO DAS CIDADES, 2010).

Em sequência, o auto de demarcação urbanística é encaminhado ao cartório de registro de imóveis, construção e aprovação do projeto de regularização fundiária do Município, para assim chegar no registro e parcelamento do solo, no qual serão abertas as matrículas de correspondentes a cada lote e portanto, retiradas da matrícula da gleba. O reconhecimento da posse, por fim, acontece através da legitimação de posse dos moradores cadastrados pelo poder público, assim a população recebe os títulos de legitimação de posse com suas respectivas matrículas resultantes do parcelamento da área. 


\section{Considerações Finais}

Diante disso, pode-se notar que a irregularidade urbana está presente em cidades grandes, médias e pequenas, sendo este último o caso das cidades analisadas. A regularização fundiária é importante para amenizar as desigualdades sociais potencializadas pelos processos de fragmentação e segregação socioespacial presentes ao longo do território das cidades. A efetivação das diferentes etapas do processo de regularização fundiária de interesse social deve acontecer mediante os princípios legais que visem a melhoria dos aspectos sociais urbanísticos e ambientais.

A etapa de regularização da base imobiliária é fundamental para as tomadas de decisões durante o processo geral, pois a partir de então é possível corrigir e atualizar os dados inerentes à base documental dos assentamentos que estão passando pelo processo de regularização fundiária de interesse social. Por meio desse passo pode realizar a análise das diversas situações presentes nos assentamentos, proporcionando assim as alterações adequadas a realidade de cada assentamento, o que facilita a redução da irregularidade fundiária por meio das titulações das áreas.

Assim, observa-se que as áreas em análise necessitam de alterações na matrícula, entre outras retificações. Outro fator que representa uma problemática para a regularização desses lotes é a desatualização dos documentos registrados em cartório ou até mesmo a falta destes. Esse último fator torna o processo mais complexo e demorado, pois gera a necessidade de utilização de demarcação urbanística, como é o caso do assentamento São Luiz - São Miguel. Caso, contrário é possível fazer a transferência direta do direito real de posse por meio da Concessão do Direito Real de Uso (CDRU).

Portanto, a realização de uma profunda análise da área ser regularizada, bem como a elaboração dos levantamentos planialtimétricos cadastrais que contribuem para a formação da base imobiliária são fundamentais para a determinação dos instrumentos legais a serem utilizados para regularizar juridicamente o assentamento caracterizado como de interesse social.

\section{Referências}

Appolinário, F. Dicionário de Metodologia Científica. 2. ed. São Paulo: Atlas, 2011. 295p.

BRASIL. Constituição (1988). Artigo no 6, de 5 de outubro de 1988. Constituição da República Federativa do Brasil. São Paulo: Saraiva, 1990.

BRASIL. Lei no 11977, de 07 de julho de 2009. Dispõe sobre o Programa Minha Casa, Minha Vida PMCMV e a regularização fundiária de assentamentos localizados em áreas urbanas. Brasília, DF.

BRASIL. Ministério das Cidades. Secretaria Nacional de Habitação e Secretaria Nacional de Programas Urbanos. Regularização Fundiária Urbana: como aplicar a Lei Federal n 11.977/2009. Brasília: 2010. Disponível em: $<$ http://www.defensoria.sp.gov.br/dpesp/repositorio/28/documentos/cartilharfcidades.pdf $>$. Acesso em: 01 mar. 2015.

INSTITUTO BRASILEIRO DE GEOGRAFIA E ESTATÍSTICA. IBGE. Característica Urbanísticas dos Entornos dos Domicílios. Censo Demográfico 2010. Rio de Janeiro: IBGE, 2012.

FERNANDES, Edésio. Regularização de Assentamentos Informais na América Latina. Cambrige: Lincoln Institute Of Land Policy, 2011.

GIL, Antonio Carlos. Como elaborar projetos de pesquisa. 4. ed. São Paulo: Atlas, 2008. 
MARICATO, Emínia. Conhecer para resolver a cidade ilegal. In: ASTRIOTA, L.B. (org.) Urbanização Brasileira: Redescobertas. Belo Horizonte: editora Arte, 2003. p. 78-96.

MARICATO, E.; et al. Cidades Rebeldes: passe livre e as manifestações que tomaram as ruas do Brasil. $1{ }^{a}$ Ed. São Paulo: Boitempo: Carta Maior, 2013.

PAIVA, João Pedro Lamana. Regularização Fundiária de Interesse Social. São Paulo: Iribid, 2012.

PROGRAMA ACESSO À TERRA URBANIZADA. Meta 1: Produtos: Capacitação da Equipe; Trabalho Social; Cartografia Básica; Regularização da Base Imobiliária.. Pau dos Ferros: Daniela, 2015. 